\title{
Functional performance of upper limb and quality of life after sentinel lymph node biopsy of breast cancer
}

\section{Desempenho funcional de membros superiores e qualidade de vida após biópsia de linfonodo sentinela para o tratamento do câncer de mama}

Fernanda S. B. Velloso', Alexandre A. Barra², Rosângela C. Dias ${ }^{3}$

\begin{abstract}
Background: Sentinel lymph node biopsy (SLNB) is commonly used for the treatment of breast cancer with minimal surgical intervention as well as with low morbidity rates of upper limbs. Objectives: The aim of the present study was to investigate possible impairments and functional performance of the upper limb on activities of daily living (ADL) and health related quality of life (HRQL) among women treated through SLNB in a Brazilian hospital and to study the association among these variables. Methods: Forty-five women (58.9 \pm 9.3 years) participated in this descriptive, cross-sectional and correlational study. The visual analogue scale (VAS) was used to quantify pain intensity/discomfort, arm circumference and shoulder range of motion (ROM) measurement were used to measure upper limb impairments. The Disabilites of Arm Shoulder and Hand questionnaire (DASH) was used to quantify functional performance of upper limb during ADL and European Organisation for Research and Treatment of Cancer - Quality of Life Questionnaire - Cancer 30 (EORTCQLQ-C30) and European Organisation for Research and Treatment of Cancer Quality of Life Questionnaire - Breast Cancer Module 23 (EORTC-BR23) were used to characterize HRQL. Results: Results revealed a 75\% prevalence of symptoms affecting upper limb (pain or discomfort in arm, shoulder) or breast, although the severity of the symptoms was only mild. Only $4.4 \%$ exhibited lymphedema and no ROM restriction was observed. There was little limitation in functional performance of the upper limb, which was associated with Arm Symptoms scale (EORTC BR-23). Impairments and functional performance of upper limb did not interfere on HRQL perception, which was considered to be good. Conclusion: SLNB caused small impairments and limitation on the functional performance of the upper limb during ADL and did not influence HRQL in our sample.
\end{abstract}

Keywords: Breast cancer; sentinel lymph node biopsy; morbidity; quality of life.

\section{Resumo}

Contextualização: A biópsia de linfonodo sentinela (BLS) é um procedimento cirúrgico minimamente invasivo para o tratamento do câncer de mama, o qual pode reduzir a morbidade de membros superiores (MMSS). Objetivos: Investigar as possíveis deficiências e o desempenho funcional de MMSS em atividades de vida diária (AVDs) e a qualidade de vida relacionada à saúde (QVRS) entre mulheres submetidas à BLS em hospital da região sudeste do Brasil e estudar a associação entre essas variáveis. Métodos: Trata-se de estudo

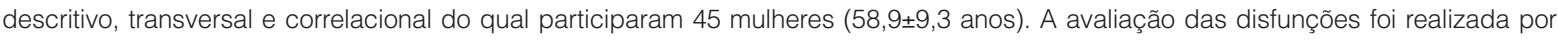
meio da medida da perimetria e da amplitude de movimento (ADM) de ombros, do relato e da quantificação da intensidade da dor/ desconforto, utilizando Escala Visual Analógica (EVA). O questionário Disabilites of Arm Shoulder and Hand (DASH) foi utilizado para medir o desempenho funcional de MMSS durante as AVDs. Para avaliar a QVRS, foram utilizados os questionários European Organisation for Research and Treatment of Cancer Quality of Life Questionnaire - Cancer 30 (EORTC QLQ-C30) e a escala de Sintomas do Braço (SB) do European Organisation for Research and Treatment of Cancer Quality of Life Questionnaire - Breast Cancer Module 23 (EORTC BR-23). Resultados: Houve alta prevalência (75\%) de sintomas que acometem MMSS (dor ou desconforto no braço ou ombro) ou mama. Apesar disso, os sintomas foram de leve intensidade. Apenas 4,4\% apresentaram linfedema. Não houve limitação da ADM de ombros, e houve pouca limitação no desempenho funcional de MMSS, o que esteve associado com a escala SB do EORTC BR-23. As disfunções e o desempenho funcional de MMSS não interferiram na percepção sobre a QVRS, que foi considerada boa. Conclusão: Nesta amostra, observou-se pouca disfunção e limitação do desempenho funcional de MMSS nas AVDs, sem influenciar a QVRS.

Palavras-chave: câncer de mama; biópsia de linfonodo sentinela; morbidade; qualidade de vida.

Received: 14/04/2010 - Revised: 08/09/2010 - Accepted: 08/02/2011

Biology, Environmental and Health Department, Centro Universitário de Belo Horizonte (UNI-BH), Belo Horizonte, MG, Brazil

${ }^{2}$ Mastology Department, Hospital Governador Israel Pinheiro, Instituto de Previdência dos Servidores do Estado de Minas Gerais (IPSEMG), Belo Horizonte, MG, Brazil

${ }^{3}$ Physical Therapy Department, Universidade Federal de Minas Gerais (UFMG), Belo Horizonte, MG, Brazil

Correspondence to: Fernanda Saltiel Barbosa Velloso, Av. Eng. Carlos Goulart, 1495, Buritis, CEP 30493-030, Belo Horizonte, MG, Brasil, e-mail: fernandasaltie|@gmail.com 


\section{Introduction $: \therefore$.}

Breast cancer is the second most prevalent type of cancer worldwide and the most common in women ${ }^{1}$. Surgical procedures and adjuvant therapy may lead to ipsilateral functional limitation in the shoulder girdle. More invasive surgery leads to a greater chance of associated morbidities ${ }^{2,3}$. The current goal is to offer a minimally invasive therapeutic approach to control the disease with less morbidity and maintaining the quality of life ${ }^{4}$. Morbidities frequently related to breast cancer surgery involve a limited shoulder range of motion, a reduction in grip strength, numbness in the shoulder, axillary and lateral chest wall areas, pain and upper limb lymphedema $a^{1,5-8}$.

Sentinel lymph node biopsy (SLNB) technique is an advance in breast cancer surgery, this technique is able to reduce morbidity without reducing the survival rate when compared to axillary lymph node dissection (ALND) ${ }^{2,9}$. Although the scientific enthusiasm over this new technique is present, the negative aspects of SLNB may be underestimated and ALND complications may be overestimated ${ }^{10}$. Moreover, physical morbidities can lead to a reduction in the quality of life, especially during the first year after surgery ${ }^{1,2,11-15}$. Healthcare professionals must understand the impact of breast cancer treatment on patient's quality of life in order to promote a better health on an individual and group levels ${ }^{16-19}$.

The International Classification of Functioning, Disability and Health (ICFDH), proposed by the World Health Organization $(\mathrm{WHO})^{20}$ in 2003, adopted a function and dysfunction model, which states that there is no linear relationship among impairments, functional limitation during activities and restriction in social participation. Also, these relationships depend on contextual aspects of the human being and his/hers environment ${ }^{20}$. Thus, it is important to understand individuals and groups of individuals submitted to similar environmental and cultural characteristics in order to allow physical therapists to identify abilities and limitations in all three ICFDH levels that comprise the health concept, and thus the therapist can establish patient-centered functional goals ${ }^{21}$.

There are several international studies aiming to detect morbidities after ALND and SLNB in the treatment of breast cancer ${ }^{1,2,5-}$ ${ }^{13,15,19,22-31}$. In Brazil, we found only three studies ${ }^{18,26,32}$ which evaluated upper limb morbidities after SLNB. Only one ${ }^{26}$ analyzed the relationship between upper limb impairments and quality of life, however there is no study that investigated the association of impairments and functional performance on the activities of daily living (ADL) of the upper limb on the health related quality of life (HRQL).

Therefore the aim of this study was to investigate possible impairments and functional performance of the upper limb on $\mathrm{ADL}$ and $\mathrm{HRQL}$ among women treated through SLNB in a southeastern Brazilian hospital and to study the relationships among these variables.

\section{Methods $: \therefore$.}

\section{Study population}

A descriptive, cross-sectional, correlational study was carried out with women who were surgically treated for breast cancer using the SLNB technique in a southeastern Brazilian hospital. Tecnecio 99 (Tc 99) was injected in the periareolar area of breast, which was followed by a lymphoscintigraphy to identify the sentinel lymph node (SLN). During the surgical procedure a gama-probe was used to identify the SLN. The average number of dissected lymph nodes was two. The participants were submitted either to breast conserving surgery (quadrantectomy) or mastectomy. The post-surgery average time in which women were evaluated was 21.3 months. Women with positive SLNB, submitted to ALND, bilateral surgery, with collagenosis, rheumatoid arthritis, shoulder girdle tendinitis, shoulder impingement syndrome, arthrosis and fibromyalgia that started prior to the surgery, those affected by cerebrovascular accident, vehicle or domestic accidents or other conditions that impaired the shoulder function and those who did not sign the consent form were excluded. From March 2004 to November 2006 one hundred and fifty four women went through breast cancer surgery and eighty fulfilled the inclusion criteria. A total of twelve patients were unable to be contacted. Three patients have died and one was hospitalized. Thirteen were unwilling to participate and six missed two consecutive appointments. Thus, 45 women were enrolled. Data were collected in 2007, from May to October. The study received approval from the hospital's ethics committee (process number CEP-HGIP: Comitê de Ética em Pesquisa - Hospital Governador Israel Pinheiro/Instituto de Previdência Social dos Servidores do Estado de Minas Gerais, Belo Horizonte, MG, Brazil, 227/06). All participants signed the consent form prior to the enrollment in this study.

\section{Data collection}

Patient selection was performed with an analysis of medical files, from which clinical variables related to breast cancer treatment were collected. The women answered a socio-demographic questionnaire that contained questions with regards to age, marital status, level of education, occupation and handedness. A visual analogue scale (VAS) was used to measure the intensity of symptoms related to pain/discomfort in the breast/ axilla and/or shoulder ${ }^{33,34}$, over the last week ${ }^{35}$.

To quantify lymphedema, a formula was used to convert upper limb circumference into a volumetric measurement, validated by Meijer et al. ${ }^{36}$. Arm circumference was determined 
using a universal metric tape. A ten percent difference between limbs was considered as lymphedema ${ }^{7}$. The values proposed by the International Society of Lymphology ${ }^{37}$ were adopted to define lymphedema's severity: minimal (difference $<20 \%$ ); moderate (difference between 20 and 40\%) and severe (>40\% difference). Two researchers were trained to collect circumference data and the measurements demonstrated a high intra and inter-tester reliability (Intraclass Correlation Coefficient (ICC) of 0.95 and 0.97 , respectively).

Shoulder passive range of motion (ROM) was measured following the protocol described by Norkin and White ${ }^{38}$ using a plastic CARCI ${ }^{\circledR}$ goniometer. Passive flexion (Fl), vertical abduction (VAb) and medial (MR) and lateral rotation (LR) were the movements investigated. Two researchers were trained to collect ROM data and the measurements demonstrated a moderate to high intra (ICC: $\mathrm{Fl}=0.79, \mathrm{VAb}=0.85, \mathrm{MR}=0.65, \mathrm{LR}=0.85$ ) and inter-tester reliability ( $\mathrm{Fl}=0.74, \mathrm{VAb}=0.80, \mathrm{MR}=0.60, \mathrm{LR}=0.75)$.

The Disabilites of Arm Shoulder and Hand (DASH) questionnaire (translated and cross-culturally adapted to Brazilian Portuguese $^{39}$ ) was used to analyze the functional performance of the upper limb on $\mathrm{ADL}$. It was applied as an interview as recommended by the authors responsible for the cross-cultural adaptation $^{39}$. Scores between the 25 and 75 quartiles were considered indicative of some degree of disability; scores below the $25^{\text {th }}$ quartile were indicative of minimal or no disability; and scores over the $75^{\text {th }}$ quartile were considered indicative of a high degree of disability ${ }^{22}$.

The European Organisation for Research and Treatment of Cancer Quality of Life Questionnaire (EORTC QLQ-C30) version 3.0 and the European Organisation for Research and Treatment of Cancer Quality of Life Questionnaire - Breast Cancer Module (EORTC BR-23) were used to measure HRQL. Both questionnaires were cross-culturally adapted to Brazilian Portuguese by Makluf ${ }^{40}$. The questionnaires were applied as an interview as recommended by the author.

Two researchers were trained in a pilot study to calibrate the instruments used in this study.

\section{Data analysis}

Socio-demographic and clinical variables were analyzed using descriptive statistics. Multiple regression analysis was used to study associations among clinical variables, functional performance of the upper limb and HRQL. Stepwise regression analysis was used to identify the best model for explaining the variation in the dependent variables: DASH questionnaire score (as representative of functional performance of upper limb) and the Global Health Status (GHS) scale from the EORTC-QLQC30 questionnaire (as representing HRQL). An $\alpha$ value of 0.05 was considered statistically significant. The variables selected to compose both models were defined: Firstly considering clinical significance as discussed by a board of specialists composed by a breast cancer specialist, a physical therapist experienced in treating breast cancer patients and a physical therapist experienced in quality of life studies; and, secondly, considering the results of the bivariate analysis on clinically important variables. Pearson's correlation test was used to determine the association between quantitative variables and the Kruskal-Wallis test was used for categorical variables. A paired Student's T-test was used to compare ROM between shoulders. The multiple regression analysis models for predicting functional performance of the upper limb considered the following factors: age, pain intensity, VAS, handedness, Breast Symptoms (BS) scale from the EORTC-BR23 and the Arm Symptoms (AS) scale from the EORTC-BR23. The model for predicting HRQL considered age, pain intensity, VAS, hormonal therapy, the pain scale from the EORTC-QLQC30, Role Functioning (RF) scale from the EORTCQLQC30, Future Perspectives (FP) scale from the EORTC-BR23, Systemic Therapy Side Effects (STSE) scale from the EORTC-BR23, BS scale, AS scale, DASH and DASH work module (DASH-WM). Data were analyzed using Minitab 14 software program.

\section{Results : :}

The socio-demographic and clinical data are summarized in Tables 1 and 2. After 21.3 months (on average) following

Table 1. Socio-demographic characteristics of participants ( $n=45)$.

\begin{tabular}{|c|c|c|}
\hline \multicolumn{3}{|c|}{ Socio-demographic characteristics of participants } \\
\hline & $n$ & $\%$ \\
\hline \multicolumn{3}{|l|}{ Age (years) } \\
\hline $30-40$ & 1 & 2.2 \\
\hline $40-60$ & 21 & 46.6 \\
\hline $60-80$ & 23 & 51.1 \\
\hline Mean (SD) & $58.9(9.3)$ & \\
\hline \multicolumn{3}{|l|}{ Marital status } \\
\hline Married & 19 & 42.2 \\
\hline Single & 11 & 24.4 \\
\hline Widowed & 9 & 20 \\
\hline Divorced & 6 & 13.3 \\
\hline \multicolumn{3}{|l|}{ Years of education } \\
\hline Up to 4 years & 2 & 4.4 \\
\hline From 4 to 8 years & 7 & 15.5 \\
\hline Over 8 years & 36 & 79.4 \\
\hline \multicolumn{3}{|l|}{ Occupation } \\
\hline Retired & 20 & 44.4 \\
\hline $\begin{array}{l}\text { Activities requiring manual effort (such as } \\
\text { housekeeping, craftwork) }\end{array}$ & 7 & 15.6 \\
\hline $\begin{array}{l}\text { Activities not requiring manual effort (such as } \\
\text { teaching, secretariat, bureaucratic services) }\end{array}$ & 18 & 40 \\
\hline
\end{tabular}


surgery approximately $75 \%$ of the women complained of pain/ discomfort, among whom $52.9 \%$ have shoulder pain and $47.1 \%$ complained of discomfort in the breast scar. Pain/discomfort intensity was considered low, as demonstrated by the mean VAS value of $2.5 \pm 1.7 \mathrm{~cm}$. Only two participants exhibited lymphedema, with differences in upper limb volumetry of 11 and $13.5 \%$ respectively. The median upper limb volumetry difference in the sample was $3.7 \%$ (median range 0.3 to $13.5 \%$ ) (Table 3). Comparison between shoulder ROM ipsilateral to surgery in relation to the contralateral side did not detect statistically significant differences (Table 3). The median DASH score was 7.5 (Interquartile range (IQR) 15.4). For the DASH-WM, the median was 0 (IQR 18.8).

HRQL (EORTC-QLQ-C30) achieved a median score on the GSH scale of 83.3 (IQD 33.3). On the RF scale, the median score was 100 (IQR 0). On the P scale, the median score was 16.7 (IQD 33.3). Values for the other scales are displayed in Table 4. The results for the BR23 questionnaire reveal median scores of 66.7 (IQD 100) on the FP scale; 19 (IQD 19.1) on the STSE scale; 8.3 (IQD 16.7) on the BS scale; and 11.1 (IQD 22.2) on the AS scale. Table 5 displays the scores for the other scales.

In the stepwise regression, the best model for explaining the variability in the functional performance of upper limb on ADL (DASH scores) was that which considers the AS scale $(\mathrm{p}<0.001)$. The model had moderate predictive power $(61.08 \%)$, which does not overrule conclusions from linear correlations.
Table 2. Treatment characteristics of participants $(n=45)$.

\begin{tabular}{|c|c|c|}
\hline Surgery type & $n$ & $\%$ \\
\hline Quadrantectomy & 40 & 88.8 \\
\hline Mastectomy & 5 & 11.1 \\
\hline \multicolumn{3}{|l|}{ Surgery side } \\
\hline Right & 24 & 53.3 \\
\hline Left & 21 & 46.6 \\
\hline \multicolumn{3}{|l|}{ Surgery ipsilaterally to handedness } \\
\hline Yes & 24 & 53.3 \\
\hline No & 21 & 46.6 \\
\hline \multicolumn{3}{|l|}{ Adjuvant treatment } \\
\hline Breast RT & 40 & 88.8 \\
\hline CT & 12 & 26.6 \\
\hline \multirow[t]{2}{*}{$\mathrm{HT}$} & 24 & 53.3 \\
\hline & \multicolumn{2}{|c|}{ Mean (SD) } \\
\hline Number of RT sessions & \multicolumn{2}{|c|}{$32(5.9)$} \\
\hline $\begin{array}{l}\text { Time between data collection and last } \\
\text { RT session (months) }\end{array}$ & \multicolumn{2}{|c|}{$18.2(9.33)$} \\
\hline Number of CT sessions & \multicolumn{2}{|c|}{$7.3(2)$} \\
\hline Period in HT (months) & \multicolumn{2}{|c|}{$16.8(8.8)$} \\
\hline Number of lymph nodes removed & \multicolumn{2}{|c|}{$2.1(1.5)$} \\
\hline $\begin{array}{l}\text { Time elapsed from surgery to data } \\
\text { collection } \\
\text { Mean/Min-Max period }\end{array}$ & \multicolumn{2}{|c|}{$21.3 / 10-42$} \\
\hline
\end{tabular}

Table 3. Functional characteristics of participants (VAS, pain/discomfort location, volumetry and ROM) ( $\mathrm{n}=45)$.

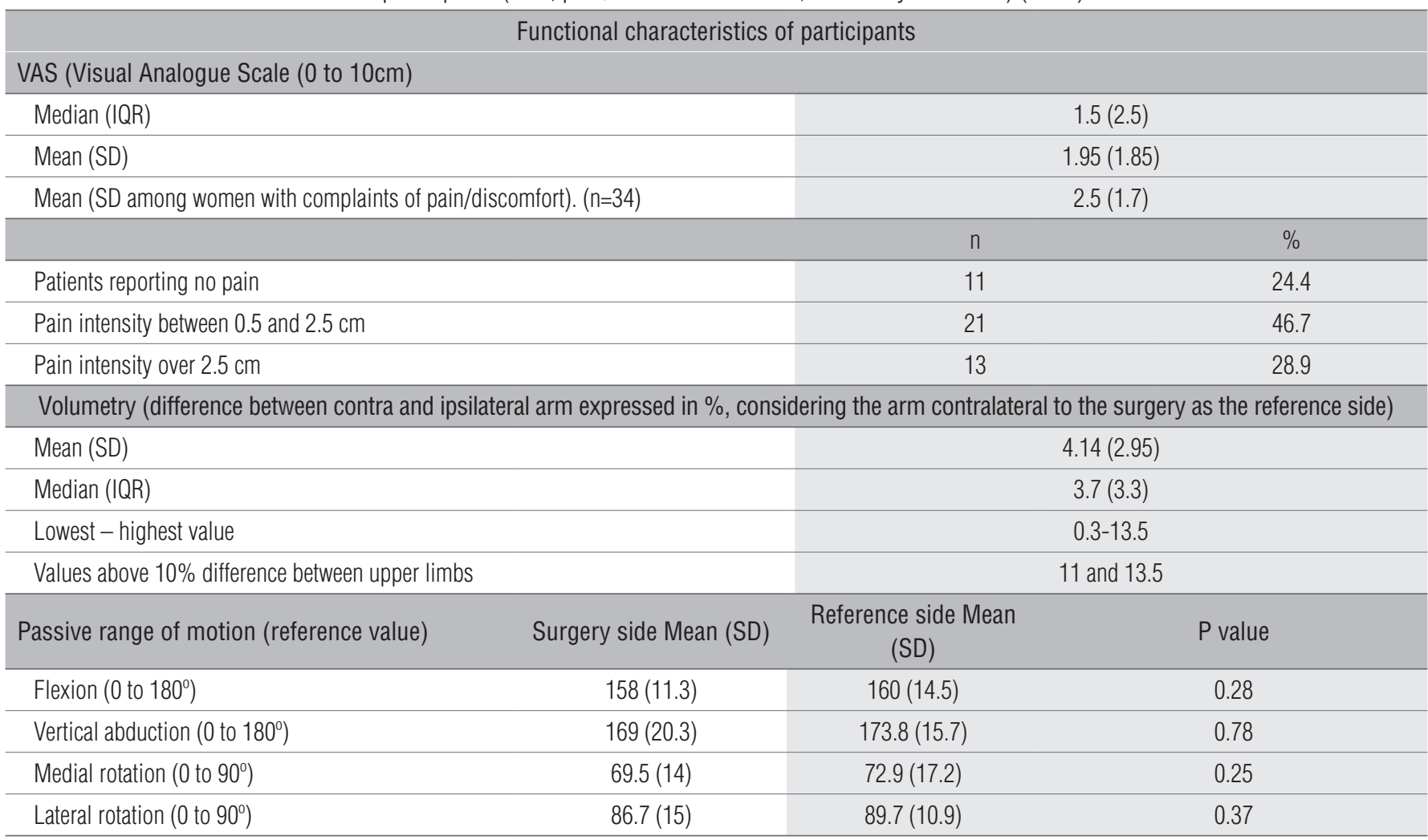

$\mathrm{IQR}=$ inter-quartile range; $\mathrm{SD}=$ standard deviation. 
Table 4. Scores on health-related quality of life questionnaire (EORTC-QLQC30) ( $n=45)$.

\begin{tabular}{lcc}
\hline \multicolumn{1}{c}{ EORTC - QLQC30 (European Organisation for Research and Treatment of Cancer - Quality of Life Questionnaire) (0 to 100) } \\
\hline Scale & Median (IQR) & Mean (SD) \\
\hline Global Health Status & $83.3(33.3)$ & $77.8(19.4)$ \\
\hline & Functional scales \\
\hline Physical functioning & $86.7(20)$ & $83(15.6)$ \\
\hline Role functioning & $100(0)$ & $91.1(19.7)$ \\
\hline Emotional functioning & $75(33.3)$ & $67.4(26.2)$ \\
\hline Cognitive functioning & $66.7(50)$ & $70.1(27.7)$ \\
\hline Social functioning & $100(0)$ & $93.8(19.9)$ \\
\hline & Symptom scales & $15.8(17)$ \\
\hline Fatigue & $11.1(22.2)$ & $4.4(9)$ \\
\hline Nausea and vomiting & $0(0)$ & $16.7(19.8)$ \\
\hline Pain & $16.7(33.3)$ & $7.4(20)$ \\
\hline Dyspnea & $0(0)$ & $18.5(28.9)$ \\
\hline Insomnia & $0(33.3)$ & $3.7(12.8)$ \\
\hline Appetite loss & $0(0)$ & $24.4(36.5)$ \\
\hline Constipation & $0(33.3)$ & $5.9(20.5)$ \\
\hline Diarrhea & $0(0)$ & $12.6(27.8)$ \\
\hline Financial difficulties & $0(0)$ & \\
\hline
\end{tabular}

$\mathrm{IQR}=$ inter-quartile range; $\mathrm{SD}=$ standard deviation .

Table 5. Scores on health-related quality of life questionnaire - Breast Cancer Module (EORTC-BR23) ( $n=45)$.

\begin{tabular}{lcc}
\hline \multicolumn{2}{c}{ EORTC - BR23 (European Organisation for Research and Treatment of Cancer - Breast Cancer Questionnaire) (0 to 100) } \\
\hline Scale & Median (IQR) & Mean (SD) \\
\hline & Functional scales & \\
\hline Body image & $100(25)$ & $33.8(25.3)$ \\
\hline Sexual functioning & $33.3(50)$ & $30.4(27.1)$ \\
\hline Sexual enjoyment * & $33.3(83.3)$ & $30.4(27.1)$ \\
\hline Future perspective & $66.7(100)$ & $51.9(39.9)$ \\
\hline & Symptom scales & $19.7(15.3)$ \\
\hline Systemic therapy side effects & $19(19.1)$ & $15.5(15.3)$ \\
\hline Breast symptoms & $8.3(16.7)$ & $13.6(18)$ \\
\hline Arm symptoms & $11.1(22.2)$ & $59.9(14.9)$ \\
\hline Upset by hair loss $\dagger$ & $66.7(0.7)$ & \\
\hline
\end{tabular}

$\mathrm{IQR}=$ inter-quartile range; $\mathrm{SD}=$ standard deviation; ${ }^{*} \mathrm{n}=31 ; \uparrow \mathrm{n}=5$.

In the stepwise regression, the best model for explaining the variability in the GSH scores from EORTC-QLQC30 (representing health-related quality of life) was that which takes into account the FP ( $\mathrm{p}=0.003)$ and STSE $(\mathrm{p}=0.020)$ variables. The predictive power was low (34.1\%), although it does not overrule conclusions from linear correlations.

\section{Discussion $: \therefore$.}

Pain/discomfort frequency rates in this study were higher than the ones observed in the literature $\mathrm{r}^{2,5,6,12,19,23,24}$. The women were asked to report their symptoms over a 7-day period, which may have increased the sensitivity. Furthermore, as this is a cross-sectional study, it was not possible to identify whether all complaints were related to surgical procedures, even though women presenting previous symptoms were excluded. Despite such results, the women pain/discomfort intensity in arm, shoulder or scar tissue is considered to be mild, as reported in previous studies ${ }^{2,14,15,25}$.

There was only $4.4 \%$ prevalence of upper limb lymphedema. The lack standardized measures for assessing lymphedema makes comparisons between studies difficult ${ }^{6,22,26,27}$. Post-SLNB upper limb lymphedema has been described as ranging from 0 
to $22 \%$ 2,5,6,18,19,22,27,28. A single criterion for classifying lymphedema should be standardized. Although the lymphedema rate after SLNB is considered to be low, follow-up studies are needed to identify the future occurrence of lymphedema in patients having undergone SLNB, as it is a condition that can affect women even 30 years after axillary surgery ${ }^{8,28}$.

Combining objective measurements of the upper limbs to subjective self-reported symptoms of arm swelling is the most reliable clinical evaluation for identifying lymphedema after breast cancer surgery $y^{6,29}$. In the present study, women with an increase in upper limb circumference reported having no symptoms related to arm swelling, but complained of scar discomfort. As the measurements showed good intra and intertester reliability, the results indicate the increase in upper limb volume may be a preexisting condition, as it did not represent discomfort in these women. The ROM of the shoulder suggests no impairment in shoulder mobility, which is in agreement with previous studies ${ }^{6,15,18,27}$.

There was little functional performance limitation of upper limbs during ADL. Only 15.5\% scored higher than 25 points on the DASH questionnaire, characterizing some limitation. No severe disability was reported. Only one study used DASH as a method for quantifying functional limitation in breast cancer patients; however it was not possible to compare with our results because the authors did not present absolute scores or described the results for SLNB alone ${ }^{22}$. Using other measurement methods the literature reports small limitations to $\mathrm{ADL}^{12,30}$. Our results also demonstrate that SLNB seems to preserve upper limb function.

The participants classified their HRQL as good. SLNB seems to have little impact on $\mathrm{HRQL}^{14,27}$. Recovery mainly occurs in the first six months ${ }^{1}$. Socio-cultural aspects may influence results regarding the self-perception of quality of life after breast cancer surgery. Given that quality of life is a multidimensional construct, it is not possible to confirm that results from European and North American studies are comparable to the data obtained from patients with other nationalities $^{31}$. In Brazil, it is possible to have regional differences, as the country is strongly affected by cultural differences ${ }^{41}$. We have found only three Brazilian studies ${ }^{18,26,32}$ concerning upper limb morbidity after SLNB for breast cancer treatment. Only one ${ }^{26}$ addressed HRQL issues, although the authors did not investigated their association to functional performance of upper limb on ADL. Thus, more comprehensive studies in Brazilian population are needed in order to understand the breast cancer patient profile worldwide.

Studying upper limb functional performance in the medium and long term is important to clarifying SLNB outcomes. The present study evaluated the association between upper limb impairments and functional performance on
ADL. The results revealed that a greater pain intensity and discomfort during arm movements (as determined by the Arm Symptoms scale on the BR23 questionnaire) denoted greater limitation in ADL. Although the AS scale takes into account pain and discomfort during arm movements and at rest, there was no association between the VAS and DASH scores in the multivariate analysis. There are conflicting results from other studies ${ }^{7,8,22}$. Perhaps pain intensity was not high enough to affect performance.

The present study found no interference of upper limb impairments on working activities. However, 20 women (44\%) were retired and answered the DASH work module considering housekeeping as their main job, as recommended by the authors of the questionnaire ${ }^{42}$. Among those employed, only $15.6 \%$ performed a job requiring manual effort. Thus, it remains unclear whether DASH scores indicate no functional performance limitation of upper limb or women were really not worried about the issue or whether these results are due to self-limitations either at home or at work as an attempt to avoid pain and/or lymphedema, as also questioned by Crane-Okada et al. ${ }^{5}$. Studies among economically active patients should be carried out to clearly evaluate the effect of SLNB sequelae on functional performance at work.

It could be assumed that surgery performed ipsilaterally to handedness would cause more functional limitation of the upper limb. Our results revealed no association between upper limb performance in ADL and handedness. This finding may be interpreted in two ways: the women were already adapted to their new condition, as the DASH questionnaire evaluates the ability to perform tasks rather than how the tasks are performed; or the surgery (whether performed ipsi or contralaterally to patient's handedness) did not cause functional limitations. The only study in which DASH was used to evaluate upper limb ability in breast cancer patients did not show such information ${ }^{22}$. However, results regarding upper limb performance and handedness described in studies using other methods were similar to those of the present study $^{19,23,24}$

There are conflicting evidence $e^{6,7,19,29,30}$ whether the type of surgical excision (mastectomy or quadrantectomy) can lead or not to higher rates of morbidity. In this study only five women went through mastectomy. Thus the sample size did not allow us to run a statistic test to analyze such association.

The results from the analysis of the impact of impairments (VAS, BS scale from the BR23 questionnaire) and functional performance of upper limbs on ADL (DASH score) on the HRQL (GHS scale from the QLQ30 questionnaire) revealed no associations. This may be explained by the low pain intensity and low degree of limitation in functional performance of upper limbs on 
$\mathrm{ADL}$, although there is no consensus in the literature on such associations ${ }^{7,14,24,26}$. HRQL was most affected by hormonal therapy (HT) (53.3\% were taking anti-estrogen drugs) or by common complaints related to aging. Thus, further studies are needed.

The present study revealed that a lower preoccupation regarding future health and fewer systemic side effects from therapy denote better HRQL scores. These results are similar to those reported previously ${ }^{19}$. As this was a cross-sectional study with a small number of patients who met inclusion criteria, the statistically significant independent variables cannot be considered as predictive of HRQL. However, this does not invalidate the direct and significant association of the dependent variables presented. Carrying out longitudinal studies with larger samples on impairments and functional performance of upper limb and HRQL in Brazil, due to the lack of published studies, would help one to define predictive models of such variables to guide and establish public health policies. Last, although other studies point out that older women are less concerned about femininity and are more resilient to adversities in life $\mathrm{e}^{16,19}$, we found no association between age and GHS, even in a group of older participants (51.1\% of the participants were 60 or older).

\section{Conclusion $: \because$.}

The results of the present study provide information for health professionals who work with breast cancer patients undergoing SLNB. We have found a high prevalence of pain among women treated for breast cancer using the SLNB technique, although pain intensity was mild. Lymphedema prevalence and passive ROM of shoulder were according to those referred in literature, confirming that SLNB is a low morbidity surgical technique. Functional limitation of upper limb on $\mathrm{ADL}$ is rare and does not affect HRQL, which was considered to be good. HRQL was most affected by patients' worries about their future health and systemic therapy symptoms.

Even though SLNB seems to leave almost no complications, one must not overlook its occurrence. It is important to perform an in-depth search for symptoms, which, although being mild, can contribute towards avoidable side effects, such as late lymphedema. Although women exhibited few symptoms, when present, they seem to affect daily living. Thus, strategies, such as patient orientation programs, should be established in order to allow women to complete functional recovery of the upper limbs.

\section{References : :}

1. Kootstra J, Hoekstra-Weebers JEHM, Rietman H, de Vries J, Baas P, Geertzen JHB, et al. Quality of life after sentinel lymph node biopsy or axillary lymph node dissection in stage I/II breast cancer patients: a prospective longitudinal study. Ann Surg Oncol. 2008;15(9):2533-41.

2. Del Bianco P, Zavagno G, Burelli P, Scalso G, Barutta L, Carraro P, et al. Morbidity comparison of sentinel lymph node biopsy versus conventional axillary lymph node dissection for breast cancer patients: results of the sentinella-GIVOM Italian randomized clinical trial. Eur J Surg Oncol. 2008;34(5):508-13.

3. Cardoso FR, Oliveira ALEAS. Avaliação postural em mulheres submetidas à mastectomia radical modificada: estudo de cinco casos. Revista Latinoamericana de Mastologia. 2004;5(1):13-8.

4. Veronesi U, Zurrida S. Present and future of sentinel node lymphadenectomy in breast cancer. Recent Results Cancer Res. 2000;157:221-7.

5. Crane-Okada R, Wascher RA, Elashoff D, Giuliano AE. Long-term morbidity of sentinel node biopsy versus complete axillary dissection of unilateral breast cancer. Ann Surg Oncol. 2008;15(7):1996-2005

6. Langer I, Guller U, Berclaz G, Koechli OR, Schaer G, Feher MK, et al. Morbidity of sentinel lymph node biopsy (SLN) alone versus SLN and completion axillary lymph node dissection after breast cancer surgery: a prospective Swiss multicenter study on 659 patients. Ann Surg. 2007;245(3):452-61.

7. Rietman JS, Dijkstra PU, Debreczeni R, Geertzen JHB, Robinson DPH, de Vries J. Impairments, disabilities and health related quality of life after treatment for breast cancer: a follow-up study 2.7 years after surgery. Disabil Rehabil. 2004;26(2):78-84.

8. Swenson KK, Nissen MJ, Ceronsky C, Swenson L, Lee MW, Tuttle TM. Comparison of side effects between sentinel lymph node and axillary lymph node dissection for breast cancer. Ann Surg Oncol. 2002;9(8):745-53

9. Pater J, Parulekar W. Sentinel lymph node biopsy in early breast cancer: has its time come? J Natl Cancer Inst. 2006;98(9):568-9.

10. Silberman AW, McVay C, Cohen JS, Altura JF, Brackert S, Sarna GP, et al. Comparative morbidity of axillary lymph node dissection and the sentinel lymph node technique: implications for patients with breast cancer. Ann Surg. 2004;240(1):1-6.
11. Rietman JS, Geertzen JH, Hoekstra HJ, Baas P, Dolsma WV, de Vries J, et al. Long term treatment related upper limb morbidity and quality of life after sentinel lymph node biopsy for stage I or II breast cancer. Eur J Surg Oncol. 2006;32(2):148-52.

12. Barranger E, Dubernard G, Fleurence J, Antoine M, Darai E, Uzan S. Subjective morbidity and quality of life after sentinel node biopsy and axillary lymph node dissection for breast cancer. J Surg Oncol. 2005;92(1):17-22.

13. Purushotham AD, Upponi S, Klevesath MB, Bobrow L, Millar K, Myles JP, et al. Morbidity after sentinel lymph node biopsy in primary breast cancer: results from a randomized controlled trial. J Clin Oncol. 2005;23(19):4312-21.

14. Arnaud S, Houvenaeghel G, Moutardier V, Butarelli M, Martino M, Tallet A, et al. Patients and surgeons' perspectives on axillary surgery for breast cancer. Eur J Surg Oncol. 2004:30(7):735-43.

15. Leidenius M, Leivonen M, Vironen J, Von Smitten K. The consequences of long-time arm morbidity in node-negative breast cancer patients with sentinel node biopsy or axillary clearance. J Surg Oncol. 2005;92(1):23-31.

16. Makluf ASD, Dias RC, Barra AA. Avaliação da qualidade de vida em mulheres com câncer de mama. Rev Bras Cancerol. 2006;52(1):49-58.

17. Belasco AGS, Sesso RCC. Qualidade de vida: princípios, focos de estudo e intervenções. In: Diniz DP, Schor N. Qualidade de vida - guias de medicina ambulatorial e hospitalar - UNIFESPEscola Paulista de Medicina. São Paulo: Manole; 2006. p. 1-10.

18. Magaldi CM, Barros ACSD, Magaldi FM, Mantese JC, Pinotti JA. Avaliação da morbidade e funcionalidade do membro superior em mulheres submetidas à linfadenectomia axilar total e biópsia de linfonodo sentinela por câncer de mama. Rev Bras Mastologia. 2005;15(1):9-14.

19. Fleissig A, Fallowfield LJ, Langridge Cl, Johnson L, Newcombe RG, Dixon JM, et al. Postoperative arm morbidity and quality of life. Results of the ALMANAC randomized trial comparing sentinel node biopsy with standard axillary treatment in the management of patients with early breast cancer. Breast Cancer Res Treat. 2006;95(3):279-93.

20. Organização Mundial da Saúde (OMS)/Organização Panamericana de Saúde (OPAS). CIF 
classificação internacional de funcionalidade, incapacidade e saúde. São Paulo, SP: Universidade de São Paulo - EDUSP; 2003

21. Sampaio RF, Mancini MC, Gonçalves GGP, Bittencourt NFN, Miranda AD, Fonseca ST. Aplicação da classificação internacional de funcionalidade, incapacidade e saúde (CIF) na prática clínica do fisioterapeuta. Rev Bras Fisioter. 2005;9(2):129-36.

22. Thomas-Maclean RL, Hack T, Kwan W, Towers A, Miedema B, Tilley A. Arm morbidity and disability after breast cancer: new directions for care. Oncol Nurs Forum. 2008;35(1):65-71.

23. Temple LK, Baron R, Cody HS 3rd, Fey JV, Thaler HT, Borgen PI, et al. Sensory morbidity after sentinel lymph node biopsy and axillary dissection: a prospective study of 233 women. Ann Surg Oncol. 2002;9(7):654-62.

24. Baron RH, Fey JV, Borgen PI, Stempel MM, Hardick KR, Van Zee KJ. Eighteen sensations after breast cancer surgery: a 5-year comparison of sentinel lymph node biopsy and axillary lymph node dissection. Ann Surg Oncol. 2007;14(5):1653-61.

25. Peintinger $F$, Reitsamer $R$, Stranzl $H$, Ralph $G$. Comparison of quality of life and arm complaints after axillary lymph node dissection vs sentinel lymph node biopsy in breast cancer patients. $\mathrm{Br}$ J Cancer. 2003;89(4):648-52.

26. Paim CA, de Paula Lima ED, Fu MR, de Paula Lima A, Cassali GD. Post Iymphadenectomy complications and quality of life among breast cancer patients in Brazil. Cancer Nurs. 2008;31(4):302-9

27. Schulze T, Mucke J, Markwardt J, Schlag PM, Bembenek A. Long-term morbidity of patients with early breast cancer after sentinel lymph node biopsy compared to axillary lymph node dissection. J Surg Oncol. 2006;93(2):109-19.

28. Armer J, Fu MR, Wainstock JM, Zagar E, Jacobs LK. Lymphedema following breast cancer treatment, including sentinel lymph node biopsy. Lymphology. 2004;37(2):73-91.

29. Helms G, Kühn T, Moser L, Remmel E, Kreienberg R. Soulder-arm morbidity in patients with sentinel node biopsy and complete axillary dissection - data from a prospective randomized trial. Eur J Surg Oncol. 2009;35(7):696-701.

30. Mansel RE, Fallowfield L, Kissin M, Goyal A, Newcombe RG, Dixon JM, et al. Randomized multicenter trial of sentinel node biopsy versus standard axillary treatment in operable breast cancer: the ALMANAC trial. J Natl Cancer Inst. 2006;98(9):599-609.

31. Ohsumi S, Shimozuma K, Kuroi K, Ono M, Imai H. Quality of life of breast cancer patients and types of surgery for breast cancer - current status and unresolved issues. Breast Cancer. 2007; 14(1):66-73
32. Ferreira BPS, Pimentel MD, Santos LC, Di Flora W, Gobbi H. Morbidade entre a pós-biópsia de linfonodo sentinela e a dissecção axilar no câncer de mama. Rev Assoc Med Bras. 2008;54(6):517-21.

33. Araújo-Soares V, Figueiredo M, Equipa de Dor. Dor: a hidra de sete cabeças. Revista Portuguesa de Psicossomática. 2001;3(2):159-84.

34. Strong J. Assessment of pain perception in clinical practice. Man Ther. 1999;4(4):216-20.

35. Scrimshaw SV, Maher C. Responsiveness of visual analogue and McGill pain scale measures. Manipulative Physiol Ther. 2001;24(8):501-4.

36. Meijer RS, Rietman JS, Geertzen JH, Bosmans JC, Dijkstra PU. Validity and intra- and interobserver reliability of an indirect volume measurements in patients with upper extremity lymphedema. Lymphology. 2004;37(3):127-33.

37. International Society of Lymphology. The diagnosis and treatment of peripheral lymphedema. Consensus document of the International Society of Lymphology. Lymphology. 2003;36(2):84-91.

38. Norkin C, White DJ. Medida do movimento articular: manual de goniometria. $2^{\mathrm{a}}$ ed. Porto Alegre: Artes Médicas; 1997.

39. Orfale AG, Araújo PMP, Ferraz MB, Natour J. Translation into Brazilian Portuguese, cultural adaptation and evaluation of the reliability of the Disabilites of the Arm, Shoulder and Hand Questionnaire. Braz J Med Biol Res. 2005;38(2):293-302.

40. Makluf ASD. Avaliação das propriedades psicométricas dos instrumentos Quality of life questionnaire (EORTC-QLQC30) e Breast cancer module (QLQ-BR23) para avaliação da qualidade de vida em mulheres operadas por câncer de mama [dissertação]. Belo Horizonte (MG): Universidade Federal de Minas Gerais; 2005.

41. Seidl EMF, Zannon CMLC. Qualidade de vida e saúde: aspectos conceituais e metodológicos. Cad Saúde Pública. 2004;20(2):580-8.

42. Hudak PL, Amadio PC, Bombardier C. Development of an upper extremity outcome measure: the DASH (Disabilities of the Arm, Shoulder, and Hand) [corrected]. Upper Extremity Collaborative Group. Am J Ind Med. 1996;29(6):602-8. 